\title{
Child Neurology: Pheochromocytoma Unveiled by Reversible Cerebral Vasoconstriction Syndrome in a Child With Neurofibromatosis Type 1
}

Micheline Lagacé, MD, Brendon Graeber, MD, FAAP, DABR, and Linda Huh, MD, FRCPC

Neurology ${ }^{\circledR}$ 2021;96:79-82. doi:10.1212/WNL.0000000000010801
Correspondence

Dr. Lagacé

Micheline.Lagace@phsa.ca

A 17-year-old right-handed boy of Korean descent developed sudden onset of palpitations with a general feeling of tremulousness and subsequent flushing. This was followed by a thunderclap headache described as if his entire head exploded and the worst pain of his life. This was accompanied by vertigo, nausea, photophobia, dyspnea, and right ocular pain with conjunctival erythema and binocular blurry vision. The latter symptoms improved after 15 minutes.

Two days later, the patient sought medical attention due to improved but persistent occipital and right-sided headache. A head CT and CT angiogram were performed. His CT was unremarkable while his $\mathrm{CT}$ angiogram showed multivessel irregular narrowing without hemorrhage (figure, A). He was transferred to our tertiary center for further evaluation and management.

The patient reported a similar episode 5 months previously. While swimming, he had sudden onset of palpitations and a severe occipital headache accompanied by vertigo and binocular blurriness. This episode resolved with rest and acetaminophen. He endorsed other milder similar episodes of exercise-induced headache in the previous 6 months.

The patient's review of systems was unremarkable, with no systemic symptoms of fever, weight loss, or rash.

The patient's medical history revealed a congenital left lower leg deformity and multiple caféau-lait (CAL) spots. A prior head MRI in Korea had been normal, and the family was told that he did not have neurofibromatosis type 1 (NF-1). He has a long-standing history of weekly headache suspicious for migraine. His development and cognition were normal.

Regarding family history, the patient's father (unavailable for examination) was suspected to have neurofibromas without CAL spots.

On physical examination, the patient's manual blood pressure was $138 / 82 \mathrm{~mm} \mathrm{Hg}$. His head circumference was $57.5 \mathrm{~cm}(+1 \mathrm{SD})$. His mental status was normal. We confirmed multiple CAL spots with more than 10 larger than $1.5 \mathrm{~cm}$. Axillary freckling and cutaneous neurofibromas were noted. He had convex bowing of his left lower extremity. His neurologic examination revealed a normal cranial nerve examination including normal funduscopy. His tone, deep tendon reflexes, strength, and coordination were normal. He had an area of decreased sensation (temperature and pinprick) on the dorsal aspect of his left foot. He had an unremarkable cardiovascular examination exempting hypertension.

Considering the clinical diagnosis of NF-1 (made on examination), our differential diagnosis for the headache and abnormal neuroimaging included NF-1 vasculopathy, transient vascular spasms, or vasculitis. An urgent MRI with vessel imaging was ordered to rule out a stroke. The imaging confirmed multivessel arterial irregular narrowing without vessel wall enhancement

From the Departments of Neurology (M.L., L.H.), and Radiology (B.G.), University of British Columbia, Vancouver, Canada.

Go to Neurology.org/N for full disclosures. Funding information and disclosures deemed relevant by the authors, if any, are provided at the end of the article. 
(figure, B). Digital subtraction angiography was not deemed necessary. Based on the patient's neuroimaging, we suspected reversible cerebral vasoconstriction syndrome (RCVS), although NF-1-associated vasculopathy could not be ruled out with certainty. An inflammatory workup, including CSF, complete blood count, C-reactive protein, erythrocyte sedimentation rate, extractable nuclear antigen, antinuclear antibodies, anti-dsDNA, C3 and C4 complement, von Willebrand factor antigen, liver enzymes, and urine analysis, was negative.

Because of the patient's hypertension, a kidney ultrasound was ordered to assess his renal vasculature, which identified a $4.3 \times 3.0 \times 3.8 \mathrm{~cm}$ right suprarenal mass suspicious for a pheochromocytoma. This diagnosis was confirmed by excess metanephrine, normetanephrine, norepinephrine, and vanillylmandelic acid in his urine. The mass was further characterized with a PET scan (not FDG-avid) and an MIBG CT scan (MIBG-avid) (figure, E). $\alpha$-Adrenergic blockade with prazosin was successfully initiated. In the days prior to surgery, additional $\beta$-blockade was obtained with propranolol. The patient underwent an uncomplicated laparoscopic right adrenalectomy. The pathology confirmed a pheochromocytoma, with margins negative for tumor involvement. Thereafter, his antihypertensive medication was successfully weaned.

As for management of the suspected RCVS and headaches, calcium channel blocker medication was not initiated initially in order to avoid hypotension with the $\alpha$-blocker, nor later because the headaches were managed successfully with acetaminophen.

At the patient's 3-month follow-up, he had no reoccurrence of severe or exercise-induced headache and he had no focal neurologic symptoms. His neuroimaging showed substantial improvement of all previously identified areas of arterial narrowing without vessel wall enhancement or new intracranial abnormality (figure, C and D). This confirmed a diagnosis of RCVS while offering no supportive elements for a component of NF-1-associated vasculopathy due to the reversibility of the vessel narrowing.

\section{Discussion}

NF-1 is a neurocutaneous syndrome caused by a germline mutation of the NF1 gene situated on chromosome 17q11.2. ${ }^{1-3}$ Incidence estimate is between $1: 2,500$ and 1 : $3,000 .^{1-5}$ This gene acts as a tumor suppressor by being a negative regulator of the RAS proto-oncogene. It encodes the neurofibromin protein affecting cell growth. ${ }^{1,2,4,5}$ It is an autosomal dominant disease, with $50 \%$ of the cases occurring de novo. This syndrome has extreme clinical variability. ${ }^{2,3}$ The diagnosis is usually made clinically using the NIH criteria, which require the presence of a minimum of 2 of the 7 established criteria. ${ }^{1,2,5}$ However, NF-1 is a multisystemic syndrome with broader involvement than suggested by its diagnostic criteria. Hypertension is a frequent complication of NF-1. It can be essential or secondary to comorbidities such as vasculopathy, including renal artery stenosis and aortic coarctation, or pheochromocytoma. ${ }^{2,5,6}$ Cerebral vasculopathy is an underrecognized NF-1 complication and is reported in $2 \%-15 \%$ of individuals with NF-1. ${ }^{6}$

A pheochromocytoma is a catecholamine-secreting neuroendocrine tumor with a general incidence of $0.002 \%-0.008 \%$. However, $30 \%$ of pheochromocytomas are associated with hereditary cancer syndromes such as von Hippel-Lindau syndrome and multiple endocrine neoplasia type $2,{ }^{1}$ but also with NF-1. Patients with NF-1 have a reported incidence of pheochromocytoma of $0.1 \%-5.7 \%$, which corresponds to at least a 10-fold higher incidence than in the general population. ${ }^{2,3,5}$ However, an autopsy series identified pheochromocytoma in up to $13 \%$ of patients with NF-1, ${ }^{5}$ and systematic screening of a small cohort of consecutive patients with NF-1 found a prevalence of pheochromocytoma of $14.6 \%$. $^{3}$ Pheochromocytoma prevalence in the hypertensive NF-1 population ranges between $20 \%$ and $50 \%$ and it presents with adrenergic symptoms. Paroxysmal attacks are described by a classic triad including headaches, tachycardia, and perspiration. 3,5,7 These headaches are often described as sudden onset, diffuse, and with severe throbbing, but descriptions similar to typical cluster headaches and migraines are not uncommon. ${ }^{7}$ Pheochromocytoma may result in serious morbidity and mortality due to sudden catecholamine release during stress, such as during surgery. ${ }^{1,3,5}$ According to recent research, pheochromocytoma associated with NF-1 has specific characteristics including an absence of familial history, unilateral disease, secretory lesion, and a benign evolution. ${ }^{3-5}$ Age at presentation is usually in the fifth decade, similar to the population without an identified genetic mutation, but older than in other genetic syndromes. ${ }^{2-5}$ Pheochromocytoma has been identified as a precipitant for $\mathrm{RCVS}^{7,8}$ and it may present with various neurologic manifestations such as stroke and hemorrhage, also seen in $\mathrm{RCVS}^{7}$ Most reported patients with pheochromocytoma did not undergo the appropriate imaging study to explore the possibility of RCVS also being present. ${ }^{7}$ Thus their true association may be underestimated.

RCVS is a clinico-radiologic diagnosis well recognized in the adult population, but underrecognized in the pediatric population due to its relative rarity. ${ }^{9,10}$ It has been reported in patients between 7 and 76 years of age with a peak occurrence at 42 years. ${ }^{8,9}$ RCVS features in adult and pediatric cases are similar, with the exception of a significant male predominance in pediatric cases. ${ }^{9}$ RCVS is characterized by recurring acute and severe thunderclap headaches, possibly accompanied by other neurologic symptoms. ${ }^{7,8,10}$ The mechanism is postulated to be a transient disturbance of the cerebrovascular tone resulting in segmental constriction of the cerebral arteries, with the exact pathophysiology still under investigation. ${ }^{8,9}$ Vasoconstriction of medium and large vessels reaches its apex 2-3 weeks following initial symptoms and is followed by a mandatory resolution within 3 months. ${ }^{7-10}$ Cerebral angiography in the acute phase will 
Figure Radiologic Findings Supporting Reversible Cerebral Vasoconstriction Syndrome Secondary to Pheochromocytoma as the Etiology of a Thunderclap Headache in a Patient with Neurofibromatosis-1
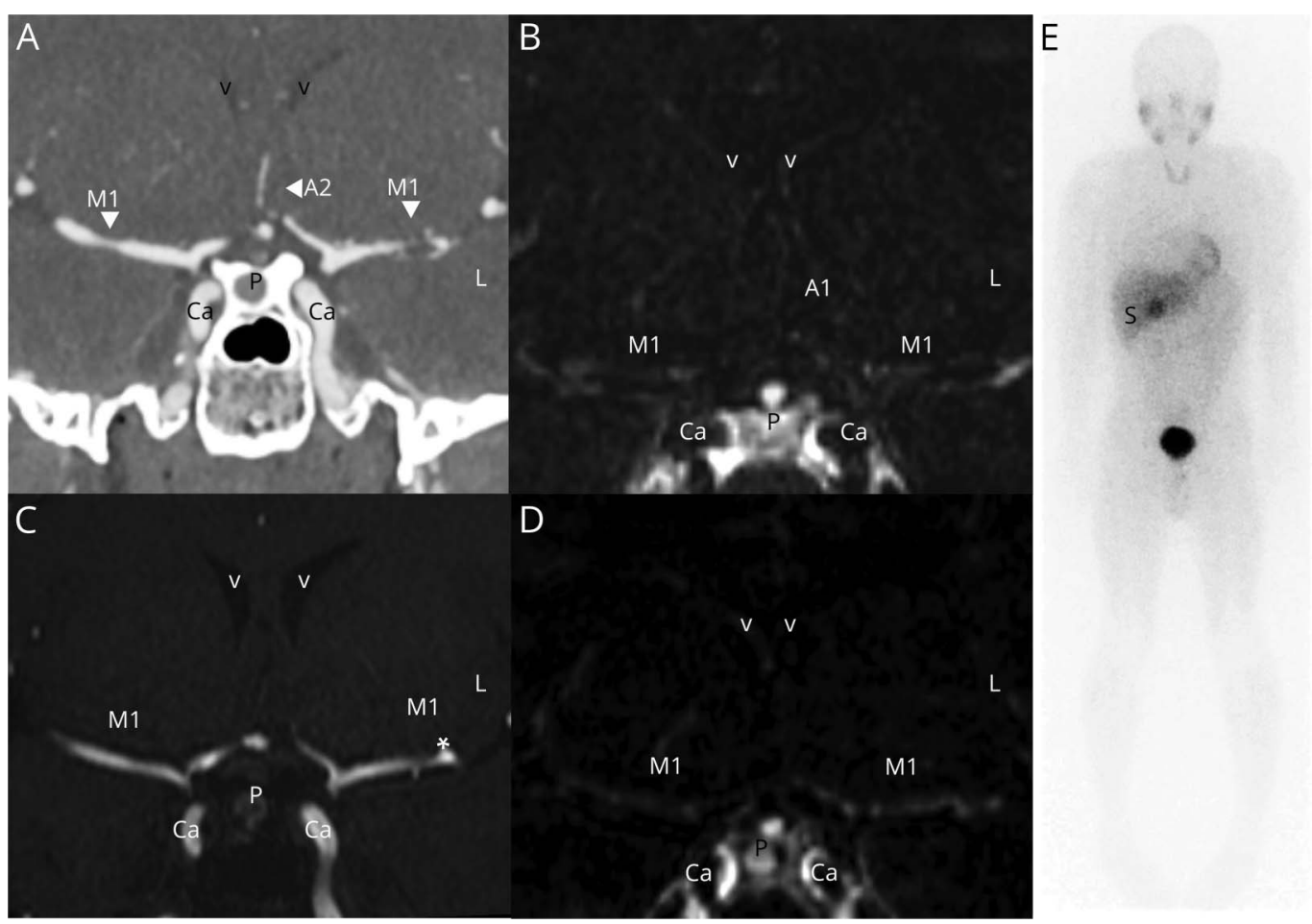

(A) Contrast-enhanced CT angiogram performed at presentation to evaluate thunderclap headache shows abnormal irregular narrowing (arrowheads) of multiple segments of the bilateral intracranial arteries including left anterior cerebral artery, bilateral middle cerebral artery, and supraclinoid right internal carotid artery. (B) A 3D fat-suppressed postcontrast T1 sampling perfection with application optimized contrast using different flip-angle evolutions (SPACE) MRI obtained the following day shows no substantial vessel wall thickening or enhancement, accounting for minor subtraction artifact (vessel lumina are black on this subtraction image). The MRI was repeated 3 months after presentation, and (C) time-of-flight magnetic resonance angiography showed substantial overall improvement of the previously identified multivessel irregular narrowing. Negligible luminal irregularity along the distal left M1 segment persisted $\left(^{*}\right)$. Once again, no vessel wall thickening or enhancement was seen (D), confirming the absence of any large vessel vasculopathy. The right suprarenal mass identified during the initial evaluation was found to be intensely I-123 MIBG-avid (E), compatible with pheochromocytoma, later confirmed via pathology. All CNS images are coronal views at the same position through the sella turcica and circle of Willis. Ca = carotid artery; $\mathrm{P}=$ pituitary gland; $\mathrm{S}=$ suprarenal mass; $\vee=$ lateral ventricle.

show segmental narrowing and dilation of one or more arteries, referred to as a string of beads. ${ }^{8}$ RCVS can be associated with focal deficits, seizure, TIA, stroke, hemorrhage, and brain edema. ${ }^{7-10}$ RCVS can be a primary condition or secondary to exposure to vasoactive substances or other precipitating factors including pheochromocytoma. ${ }^{7,8,10}$ In RCVS occurring with pheochromocytoma, it is believed that the vasoconstriction is the result of the high level of circulating catecholamines. ${ }^{7}$ RCVS is usually reported as a single lifetime episode, especially in pediatric cases. ${ }^{8-10}$ Calcium channel blockers are recognized to reduce the headache symptoms, although they do not modify ischemic and hemorrhagic complications. ${ }^{8-10}$

We present the first reported case in the literature that connects the known relationships between NF-1 with pheochromocytoma and RCVS with pheochromocytoma. This is in addition to the rare pediatric presentation of pheochromocytoma in NF-1. ${ }^{1,4}$

Current guidelines do not recommend screening for pheochromocytoma in all patients with NF-1. ${ }^{4,5}$ Our case emphasizes the importance of investigating for this associated condition in hypertensive patients with NF-1. ${ }^{3,5}$ It contributes to the discussion raised by research groups about systematic screening for pheochromocytoma in all patients with NF-1 starting in late childhood, particularly prior to elective surgery and pregnancy. ${ }^{4,5}$ Finally, our case stresses the need to consider appropriate neuroimaging and the diagnosis of RCVS in patients with pheochromocytoma with neurologic symptoms and emphasizes the importance of including RCVS in the pediatric differential diagnosis of a thunderclap headache.

\section{Acknowledgment}

The authors thank the neurology, nephrology, endocrinology, and general surgery teams who helped to care for this patient.

\section{Study Funding}

No targeted funding reported.

\section{Disclosure}

The authors report no disclosures relevant to the manuscript. Go to Neurology.org/N for full disclosures. 
Appendix Authors

\begin{tabular}{lll}
\hline Name & Location & Contribution \\
\hline $\begin{array}{l}\text { Micheline } \\
\text { Lagacé, MD }\end{array}$ & $\begin{array}{l}\text { British Columbia } \\
\text { Children's Hospital, } \\
\text { Vancouver }\end{array}$ & $\begin{array}{l}\text { Drafting and revision of } \\
\text { manuscript for intellectual } \\
\text { content }\end{array}$ \\
\hline $\begin{array}{l}\text { Brendon } \\
\text { Graeber, MD, }\end{array}$ & $\begin{array}{l}\text { British Columbia } \\
\text { Children's Hospital, } \\
\text { FAAP, DABR }\end{array}$ & $\begin{array}{l}\text { Drafting and revision of } \\
\text { manuscript for intellectual } \\
\text { content }\end{array}$ \\
\hline $\begin{array}{l}\text { Linda Huh, MD, } \\
\text { FRCPC }\end{array}$ & $\begin{array}{l}\text { British Columbia } \\
\text { Children's Hospital, } \\
\text { Vancouver }\end{array}$ & $\begin{array}{l}\text { Drafting and revision of } \\
\text { manuscript for intellectual } \\
\text { content }\end{array}$ \\
\hline
\end{tabular}

\section{References}

1. Giovannoni I, Callea F, Boldrini R, Inserra A, Cozza R, Francalaci P. Malignant pheochromocytoma in a 16-year-old patient with neurofibromatosis type 1. Pediatr Dev Pathol 2014;17:126-129.
2. Hirbe AC, Gutmann DH. Neurofibromatosis type 1: a multidisciplinary approach to care. Lancet Neurol 2014;13:834-843.

3. Zinnamosca L, Petramala L, Cotesta D, et al. Neurofibromatosis type 1 (NF1) and pheochromocytoma: prevalence, clinical and cardiovascular aspects. Arch Dermatol Res 2011;303:317-325

4. Gruber LM, Erickson D, Babovis-Vuksanovic D, Thompson GB, Young WF, Bancos I. Pheochromocytoma and paraganglioma in patients with neurofibromas type 1. Clin Endocrinol 2017;86:141-149.

5. Moramarco J, El Ghorayeb N, Dumas N, et al. Pheochromocytomas are diagnosed incidentally and at older age in neurofibromatosis type 1. Clin Endocrinol 2017;86: 332-339.

6. Kass B, Huisman T, AGM Tekes A, Bergner A, Blakeley JO, Jordan LC. Spectrum and prevalence of vasculopathy in pediatric neurofibromatosis type 1. J Child Neurol 2012;28:561-569.

7. Anderson NE, Chung K, Willoughby E, Croxson MS. Neurological manifestations of phaeochromocytomas and secretory paragangliomas: a reappraisal. J Neurol Neurosurg Psychiatry 2013;84:452-457.

8. Ducros A. Reversible cerebral vasoconstriction syndrome. Lancet Neurol 2012;11: 906-917.

9. Coffina SW, Fryer RH. Reversible cerebral vasoconstriction syndrome in pediatrics: a case series and review. J Child Neurol 2017:614-623.

10. Probert R, Saunders D, Ganesan V. Reversible cerebral vasoconstriction syndrome: rare or underrecognized in children? Dev Med Child Neurol 2013;55: 385-389.

\section{NEW EPISODE}

ค $\underset{\text { PODCAST }}{\text { Neurology }}$

January 12, 2021

\section{Worldwide Incidence and Prevalence of Neuromye- litis Optica: A Systematic Review (see p. 59)}

In the first segment, Will Rondeau talks with Dr. Lee Schwamm about the latest on cryptogenic stroke. In the second part of the podcast, you'll hear Dr. Stacey Clardy's interview with Dr. Zsolt Illes about the worldwide impact of neuromyelitis optica.

Disclosures can be found at Neurology.org.

CME Opportunity: Listen to this week's Neurology ${ }^{\circledR}$ Podcast and earn 0.5 AMA PRA Category 1 CME Credits ${ }^{\mathrm{TM}}$ by completing the online podcast quiz.

\section{Get NeuroReady!}

Preparing for the neurology boards? Up for recertification? Looking for a solid foundational knowledge in neurology? Get ready with the AAN's convenient online courses-NeuroReady: Board Prep Edition or NeuroReady: Continuing Certification Edition, and the new NeuroReady: Advanced Practice Provider Edition. Includes 12 months of access. Get ready to review, self-assess, and succeed at AAN.com/NeuroReady. 


\section{Neurology}

\section{Child Neurology: Pheochromocytoma Unveiled by Reversible Cerebral Vasoconstriction Syndrome in a Child With Neurofibromatosis Type 1 \\ Micheline Lagacé, Brendon Graeber and Linda Huh}

Neurology 2021;96;79-82 Published Online before print September 9, 2020

DOI 10.1212/WNL.0000000000010801

This information is current as of September 9, 2020

\section{Updated Information \&} Services

References

Subspecialty Collections

Permissions \& Licensing

Reprints including high resolution figures, can be found at: http://n.neurology.org/content/96/2/79.full

This article cites 9 articles, 1 of which you can access for free at: http://n.neurology.org/content/96/2/79.full\#ref-list-1

This article, along with others on similar topics, appears in the following collection(s):

All Pediatric

http://n.neurology.org/cgi/collection/all_pediatric

Endocrine

http://n.neurology.org/cgi/collection/endocrine

Neurofibromatosis

http://n.neurology.org/cgi/collection/neurofibromatosis

Other cerebrovascular disease/ Stroke

http://n.neurology.org/cgi/collection/other_cerebrovascular_disease_st roke

Pediatric headache

http://n.neurology.org/cgi/collection/pediatric_headache

Information about reproducing this article in parts (figures,tables) or in its entirety can be found online at:

http://www.neurology.org/about/about_the_journal\#permissions

Information about ordering reprints can be found online:

http://n.neurology.org/subscribers/advertise

Neurology ${ }^{\circledR}$ is the official journal of the American Academy of Neurology. Published continuously since 1951, it is now a weekly with 48 issues per year. Copyright () 2020 American Academy of Neurology. All rights reserved. Print ISSN: 0028-3878. Online ISSN: 1526-632X.

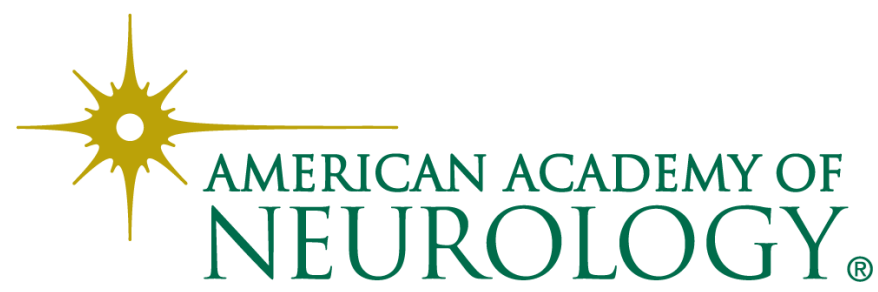

